\title{
Efeito da Temperatura, Luminosidade e Forma de Armazenamento na Estabilidade da Solução de Hipoclorito de Sódio a $\mathbf{1 \%}$ The Influence of Temperature, Light Exposure and Storage in the Stability of 1\% Sodium Hipochlorite Solution
}

\author{
* Marcus Vinicius Reis Só \\ **Cíntia Muniz Couto \\ *** Orlando Limongi \\ **** José Antônio Poli de Figueiredo
}

\begin{abstract}
RESUMO
Com o propósito de verificar a estabilidade da solução de hipoclorito de sódio a $1 \%$ frente à interferência de fatores como temperatura, luminosidade e forma de armazenamento foram elaboradas 6 amostras da mesma. Cinco delas foram estocadas em vidro âmbar, uma em frasco plástico e posteriormente colocadas em diferentes locais para que se pudesse avaliar isoladamente a interferência de cada um dos fatores citados. $\mathrm{O}$ aumento da temperatura proporcionou maiores variações no teor de cloro ativo da solução de hipoclorito de sódio. A presença de luminosidade e a forma de armazenamento não inflúram de forma significativa na diminuição do teor de cloro ativo da solução de hipoclorito de sódio.
\end{abstract}

\section{PALAVRAS-CHAVE}

hipoclorito de sódio, substâncias químicas.

\section{INTRODUCÃO}

A utilização de uma substância irrigadora concomitante ao uso do instrumento endodôntico durante o preparo dos canais radiculares é de fundamental importância em Endodontia. IMURA, ZUOLO (1988) acreditam que o hipoclorito de sódio é a substância que reúne as melhores propriedades físico-químicas e por isso é o mais comumente utilizado.

O hipoclorito de sódio é a substância química mais empregada para a irrigação dos canais radiculares, durante a terapia endodôntica. Recomendado por DAKIN (1915) para a limpeza dos ferimentos de soldados durante a $1{ }^{\text {a }}$ Guerra Mundial, este provou ter vencido a barreira do tempo e tornado-se a partir dos trabalhos de GROSSMAN, MEIMAN (1941) amplamente difundida na Endodontia.

Devido a instabilidade do hipoclorito de sódio, MAISTO (1967) recomendou conservá-lo em local fresco, ao abrigo da luz e renovado a cada 3 meses. Fatores como luminosidade, temperatura e forma de armazenamento da solução podem fazer com que o teor de cloro se altere (GAMBARINI; DE LUCA; GEROSA , 1998).

\section{REVISÃO DA LITERATURA}

O hipoclorito de sódio tornou-se importante para a Endodontia devido ao grande número de propriedades, particularmente, importantes para o tratamento dos canais radiculares. Entre estas podemos destacar o seu efeito bactericida (LEONARDO, LEAL,1991), dissolução de matéria orgânica (GROSSMAN, MEIMAN, 1941; SÓ et al., 1997), pH alcalino( LEONARDO, LEAL, 1998), desodorizante e clareador (LEONARDO, LEAL, 1991).

A par da importância que este composto halogenado tem para a Endodontia, é importante salientar que a referida substância pode apresentar-se quimicamente instável no que tange ao seu teor de cloro ativo (SÓ; OSDEBERG; KLYMUS ,2000) e que isto pode ser influenciado por uma série de fatores como por exemplo, temperatura, luminosidade, forma de armazenagem, $\mathrm{pH}$, presença de matéria orgânica.

A capacidade de dissolução de colágeno de soluções de hipoclorito de sódio a $2,6 \%$ e $5,2 \%$ foi comparada em temperatura ambiente $\left(21^{\circ} \mathrm{C}\right)$ e temperatura corporal $\left(37^{\circ} \mathrm{C}\right)$. A solução de hipoclorito de sódio a $2,6 \%$ na temperatura corporal mostrou ser igualmente efetiva como agente de dissolução de colágeno quando comparada com a solução de hipoclorito de sódio a $5,2 \%$ nas temperaturas de $21^{\circ} \mathrm{C}$ e $37^{\circ} \mathrm{C}$ (CUNNINGHAM, BALEKJIAN, 1980)

CUNNINGHAM, BALEKJIAN (1980) compararam a atividade bactericida do hipoclorito de sódio a $2,6 \%$ em duas temperaturas $\left(22^{\circ} \mathrm{C}\right.$ e $\left.37^{\circ} \mathrm{C}\right)$ frente a cinco microrganismos. O tempo requerido para o hipoclorito de sódio a $2,6 \%$ em duas tempe- raturas eliminar estes microrganismos foi significativamente menor na temperatura de $37^{\circ} \mathrm{C}$ quando comparada com os $22^{\circ} \mathrm{C}$.

Avaliando os efeitos da temperatura, variação da concentração, e tipo de tecido na ação solvente de soluções de hipoclorito de sódio, ABOU-RAS, OGLESBY (1981) verificaram que o aquecimento a 140.F aumenta a eficácia do hipoclorito de sódio em dissolver os tecidos. Os tecidos frescos foram os mais rapidamente dissolvidos, seguidos pelos necróticos e fixados. A concentração de $5,2 \%$ foi mais efetiva do que a $2,6 \%$ independente do tipo de tecido ou da temperatura da solução.

FABIAN, WALKER (1982) estudaram a estabilidade química de três diluições de hipoclorito de sódio, na tentativa de estabelecer um prazo de validade para estas soluções. Os resultados mostraram que soluções diluídas de hipoclorito de sódio a $1 \%$ são quimicamente estáveis, uma vez que $90 \%$ do cloro disponível estava presente 23 meses após. Um prazo de validade apropriado para estas soluções, armazenadas em frascos de vidro âmbar, foi de 23 meses.

Segundo HARRISON (1987), aumentando-se a temperatura das soluções de hipoclorito de sódio às propriedades antimicrobianas e de dissolução tecidual tornam-se intensificadas. Por outro lado, a diluição de um hipoclorito de sódio a $5,25 \%$ diminuirá significativamente estas ações. 
PÉCORA et al. (1987) estudaram o tempo de vida da solução de Dakin armazenadas em vidro âmbar em diversas condições de temperatura, ou seja, à luz solar, à sombra - temperatura ambiente e, em geladeira à $9^{\circ} \mathrm{C}$ e isento de luz. Eles observaram que após 4 meses a solução perdia $80 \%$ de seu teor de cloro quando deixada a receber luz solar, $60 \%$ à temperatura ambiente e apenas $20 \%$ quando conservada a baixa temperatura e isenta de luz.

0 propósito do estudo de PISKIN, TÜRKÜN (1995) foi investigar os efeitos da temperatura de armazenagem, concentração e tempo sobre a estabilidade de 3 diferentes marcas comerciais de hipoclorito de sódio. Todas as soluções mostraram degradação em função do tempo. Entretanto esta ocorreu muito lentamente, exceto para o grupo da solução com $5 \%$ de cloro disponível e a $24^{\circ} \mathrm{C}$. Soluções contendo $0,5 \%$ de cloro livre, armazenadas a $4^{\circ} \mathrm{C}$ e $24^{\circ} \mathrm{C}$ demonstraram satisfatória estabilidade aos 200 dias. Nenhuma diferença significante foi encontrada entre as 3 marcas comerciais com respeito a sua estabilidade química.

A temperatura da solução de hipoclorito de sódio exerce uma influência significativa em seus efeitos antibacterianos. Uma elevação de $10^{\circ} \mathrm{C}$ na temperatura da solução promove uma redução de aproximadamente 50 a $60 \%$ no tempo necessário para destruir microrganismos. Por sua vez, se a temperatura da solução é reduzida em $10^{\circ} \mathrm{C}$, o tempo necessário para ter efeito bactericida é elevado em cerca de duas vezes.

GAMBARINI, DE LUCA, GEROSA (1998) estudaram o efeito do aquecimento do hipoclorito de sódio a $5 \%\left(50^{\circ} \mathrm{C}\right)$ sobre a estabilidade da solução. $O$ teste iodométrico foi empregado para avaliar o grau de degradação das soluções aquecidas e não aquecidas em um período de 30 dias. Os resultados demonstraram que todas as amostras exibiram um mínimo, porém gradual degradação com o passar do tempo. Entretanto, não houve diferença estatisticamente significativa entre os dois grupos.

A alcalinidade cáustica, induzida por hidróxidos, é um importante fator de estabilização da solução de hipoclorito de sódio. Por elevar o $\mathrm{pH}$ acima de 11, ela retarda a reação de oxirredução que resulta na formação de clorato. A velocidade de oxidação do hipoclorito a clorato é baixa em $\mathrm{pH}$ alcalino, não sendo, contudo, anulada (SIQUEIRA Jr, LOPES, 1999).

SÓ, OSDEBERG, KLYMUS, (2000) verificaram o teor de cloro ativo de seis marcas comerciais de hipoclorito de sódio, através do método iodométrico. Com base nesta avaliação, os autores concluíram que os

hipocloritos de sódio averiguados são substâncias quimicamente instáveis. Quatro das seis amostras testadas tiveram redução na concentração de cloro disponível. Neste estudo os autores comprovaram que todas as soluções estavam armazenadas em frascos plásticos.

A estabilidade química da solução de hipoclorito de sódio a $0,5 \%$ em diferentes $\mathrm{pH}$ sob refrigeração a 5 .C foi estudada por SIQUEIRA, NICOLETTE,SANTOS, (2000). 0 s resultados mostraram que para o $\mathrm{pH} 7 \mathrm{e}$ 8 a concentração de cloro alcançou $0,45 \%$ em 7 e 16 dias respectivamente. Sendo assim, o $\mathrm{pH}$ mais próximo do neutro possui menor estabilidade química quando comparado às soluções com $\mathrm{pH}$ mais alcalino.

0 objetivo deste trabalho foi avaliar o efeito da luminosidade, temperatura e forma de armazenamento sobre a estabilidade

\begin{tabular}{|c|c|c|}
\hline ANÁLISE & MÉTODO & RESULTADO \\
\hline $\begin{array}{l}\text { Cloro Ativo-determinaçãol } \\
\text { Cloro Ativo-determinação2 } \\
\text { Cloro Ativo-determinação3 }\end{array}$ & $\begin{array}{l}\text { Iodometria } \\
\text { Iodometria } \\
\text { Iodometria }\end{array}$ & $\begin{array}{l}1,06 \mathrm{mg} / \mathrm{L} \mathrm{Cl} 2 \\
1,04 \mathrm{mg} / \mathrm{L} \mathrm{Cl} 2 \\
1,02 \mathrm{mg} / \mathrm{L} \mathrm{Cl} 2\end{array}$ \\
\hline
\end{tabular}

Quadro 2: Avaliação do teor de cloro ativo da solução de NaOCl 1\%-Frascos âmbar.

\begin{tabular}{|ccc|}
\hline ANÁLISE & MÉTODO & RESULTADO \\
\hline Cloro Ativo-determinação1 & Iodometria & $1,01 \mathrm{mg} / \mathrm{L} \mathrm{Cl} 2$ \\
Cloro Ativo-determinação2 & Iodometria & $1,06 \mathrm{mg} / \mathrm{L} \mathrm{Cl} 2$ \\
Cloro Ativo-determinação3 & Iodometria & $1,10 \mathrm{mg} / \mathrm{L} \mathrm{Cl} 2$ \\
\hline
\end{tabular}

De posse da análise físico-química das amostras, as mesmas foram dispostas, por um período de 60 dias, da seguinte forma:

- 02 frascos âmbar com as soluções foram guardados em 2 ambientes distintos: 01 foi guardado em um armário ventilado ao abrigo da luz, e o outro colocado próximo a uma janela recebendo a luz do dia, porém sem a interferência direta dos raios solares. Ambos se mantiveram com a temperatura sempre aproximada (ambiente), de tal forma que se manteve um termômetro dentro do armário e outro próximo janela. Dessa forma, pretendeu-se observar a interferência da luminosidade sobre a estabilidade do hipoclorito de sódio.

- 02 frascos âmbar com as soluções foram guardados em 2 ambientes distintos: 01 foi guardado em um armário ventilado ao abrigo da luz à temperatura ambiente, e o outro colocado em uma estufa bacteriológica à temperatura constante de $40^{\circ} \mathrm{C}$. Com isso, pretendeu-se observar o efeito da temperatura sobre a estabilidade da solução de hipoclorito de sódio. da solução de hipoclorito de sódio a 1\% após 60 dias de exposição a estes fatores.

\section{MATERIAL E MÉTODO}

Para a realização do experimento foi solicitada à Farmácia Escola da Universidade Luterana do Brasil a produção de 6 litros de hipoclorito de sódio a $1 \%$, que foram armazenados em 5 frascos de vidro cor âmbar com tampa, contendo 1 litro da solução em cada um e em 1 recipiente plástico com tampa, de cor branca também possuidor de um litro da mesma solução.Posteriormente, encaminhou-se as amostras a um laboratório de análise de águas ("QUIMIOAMBIENTAL") para que fosse procedida a titulação do teor de cloro disponível, através do método Iodometria, conforme o quadro 1 e 2 abaixo demonstram. 


\begin{tabular}{|lcccc|}
\hline \multicolumn{5}{l}{ Quadro 2: Avaliação do teor de cloro ativo da solução de NaOCl 1\%-Frascos âmbar. } \\
\hline ANÁLISE & MÉTODO & FATOR & FRASCO & RESULTADO \\
\hline Cloro Ativo & Iodométrico & Luminos/janela & Âmbar & $0,78 \%$ \\
Cloro Ativo & Iodométrico & Luminos/armário & $\hat{A} m b a r$ & $0,75 \%$ \\
Cloro Ativo & Iodométrico & Temper/estufa & Âmbar & $0,54 \%$ \\
Cloro Ativo & Iodométrico & Temper/armário & Âmbar & $0,75 \%$ \\
Cloro Ativo & Iodométrico & Armazen/armário & Âmbar & $0,75 \%$ \\
Cloro Ativo & Iodométrico & Armazen/armário & Plástico & $0,71 \%$ \\
\hline
\end{tabular}

\section{DISCUSSÃO}

Não pairam dúvidas na literatura endodôntica de que o hipoclorito de sódio venceu a prova do tempo. Empregado desde antes da metade do século passado em Endodontia e largamente utilizado nos dias de hoje, podemos nos encorajar a dizer que dificilmente encontraremos uma substância substituta para a irrigação dos canais radiculares.

Isso se deve com certeza a duas importantes propriedades que esta substância apresenta na terapia dos canais radiculares; dissolução tecidual (GROSSMAN, MEIMAN, 1941; SÓ et al.,1997) e atividade antibacteriana (LEONARDO, LEAL ,1991).

0 hipoclorito de sódio exerce sua ação a sob a forma de ácido hipocloroso não dissociado quando em soluções neutras ou ácidas e sob a forma de ânion hipoclorito quando em soluções alcalinas. Através do ácido hipocloroso têm-se soluções com intensa atividade bactericida, porém com uma maior instabilidade química, onde há uma diminuição no teor de cloro ativo da solução. Por outro lado, o inverso é verdadeiro, pois a presença do ânion hipoclorito deixa a solução mais estável e com um menor poder antibacteriano.

Muitos trabalhos na literatura retrataram a verificação do teor de cloro ativo de diferentes marcas comerciais de hipoclorito de sódio (SÓ, OSDEBERG, KLYMUS, 2000), observando queda no teor de cloro disponível das soluções mesmo quando estas estão dentro do prazo de validade. Isto denota a instabilidade química desta substância que aliada a determinados fatores externos podem determinar diminuições muito significativas nos teores de cloro ativo das soluções de hipoclorito de sódio.

Fatores como luminosidade, temperatura e forma de armazenamento são apenas alguns dos fatores capazes de interferir na estabilidade química das soluções. Neste trabalho foi possível verificar que independente do fator de variação obteve-se redução no teor de cloro disponível das soluções.

$\mathrm{O}$ fator luminosidade nessa pesquisa não mostrou diferenças quando a solução permaneceu na sombra de uma janela e no armário $(0,78 \%$ e $0,75 \%)$ respectivamente. Os trabalhos de PÉCORA et al. (1987) demonstraram perdas de até $80 \%$ da concen- tração de cloro ativo quando as soluções de hipoclorito de sódio foram expostas à radiação solar. Em nosso trabalho, o frasco, com hipoclorito de sódio, foi exposto a luz do dia, mas não recebeu diretamente a radiação solar e talvez este fato possa explicar uma perda não tão significativa na concentração da solução.

A permanência da solução na temperatura de $40^{\circ} \mathrm{C}$ por todo o período experimental, permitiu verificar uma perda de quase $50 \%$ na concentração de cloro, quando comparada com o frasco âmbar que estava em um armário ventilado, à temperatura ambiente e ao abrigo da luz. Este resultado não está consoante com os de GAMBARINI, DE LUCA,GEROSA, (1998) que observaram uma redução gradual na concentração de cloro ativo, porém não significativa quando comparada com o grupo onde não houve

É preciso que se diferencie o efeito do aumento da temperatura ao longo de um período de tempo sobre o teor de cloro ativo do hipoclorito de sódio, da elevação da temperatura da solução no momento do seu uso. A elevação da temperatura da substância previamente ao seu emprego no canal radicular, potencializa suas ações sobre a matéria orgânica e microrganismos, conforme indicam os trabalhos de CUNNINGHAM, BALEKJIAN (1980); ABOURAS, OGLESBY (1981); HARRISON (1987); PISKIN, TURKÜN (1995). do hipoclorito de sódio, nossos resultados apontam para similaridades de comportamento entre as duas formas de armazenamento empregadas, desde que as outras variações estejam isoladas. MAISTO (1967) recomendou guardar a solução de hipoclorito de sódio ao abrigo da luz e em lugar fresco. Talvez a manutenção dos frascos da forma recomendada, possa ter ajudado na obtenção dos nossos resultados.

Por fim, acreditamos que estes fatores relacionados com estabilidade da solução de hipoclorito de sódio, aliados a outros que necessitam ser estudados, deverão ajudar o clínico a otimizar o emprego desta importante substância irrigadora, buscando nela o máximo dos seus efeitos naquilo que nos propomos durante o tratamento endodôntico. aumento de temperatura.

Com relação à forma de armazenamento

\section{CONCLUSÕES}

Baseados em nossa metodologia e resultados e lícito concluir que:

1- Independente dos fatores estudados, observou-se diminuição no teor de cloro ativo de todas as soluções de hipoclorito de sódio, ao final do período experimental.

2- 0 efeito da temperatura (aumento) proporcionou maiores variações no teor de cloro ativo da solução de hipoclorito de sódio.

3- A presença de luminosidade e a forma de armazenamento não influíram de forma significativa na diminuição do teor de cloro ativo da solução de hipoclorito de sódio.

\section{ABSTRACT}

The aim of this study was to analyse the stability of $1 \%$ sodium hypochlorite to interference factors such as temperature, light exposure and means of storage. Six samples were used in this study, being five stored in dark brown glass recipients and one in a plastic recipient. The samples were placed at different sites in which one of the variables would be included, in order to help the assessment of such variables. The raise in temperature lead to variations in chloride release from the solution tested. Light exposure and storage did not interfere significantly in the release of chloride from the solution.

\section{KEYWORDS}

sodium hipochlorite, chemical substances

\section{REFERÊNCIAS BIBLIOGRÁFICAS}

ABOU-RASS,M.; OGLESBY, S.W. The effects of temperature, concentration and tissue type on the solvent ability of sodium hypochlorite. J. Endod., Baltimore, v.7, no.8, p.376-7, Aug,1981.

CUNNINGHAM,W.T; BALEKJIAN, A . Y. Effect of temperature on collagendissolving ability of sodium hypochlorite endodontic irrigant. Oral Surg.Oral Med. Oral Pathol. Oral Radiol. Oral Endod., St Louis, v.49, no.2, p.1757,Feb.1980.

DAKIN , H.D. In the use of certain antisseptic substances in the treatment of infected wounds. Br. Med. J., London, v.2, p. 318-320, Aug. 1915.

FABIAN,T ; WALKER,S.E. Stability of sodium hypochlorite solutions. A. J.Hosp.Pharm., Bethesda, v.39, p.1016-7, June, 1982.

GAMBARINI, G. ; DE LUCA, M. ; GEROSA, R. Chemical stability of heated sodium hypochlorite endodontic irrigants. J. Endod., Baltimore ,v.24, no.6, p. 432-433, June, 1998. 
GROSSMAN, L.I. ; MEIMAN , B.W. Solution of pulp tissue by chemical agents. J. Am. Dent. Assoc., Chicago, v.28, no.2, p.223-225, Feb 1941.

HARRISON,J.W. Irrigação do sistema de canal radicular. Endodontia- clínicas odontológicas da América do Norte. São Paulo: Panamericana. p.175-7, 1987.

IMURA, N.; ZUOLO , M.L. Preparo químico-mecânico do sistema de canais radiculares In: Endodontia: procedimentos clínicos em endodontia. São Paulo: Pancast, 1988. p.123-125.

LEONARDO, M.R. Preparo biomecânico dos canais radiculares In: LEONARDO, M.R.; LEAL, J.M. Endodontia: tratamento de canais radiculares. 2 ed. São Paulo: Panamericana, 1991. Cap. 15, p. 224-239.

LEONARDO, M.R. Preparo biomecânico dos canais radiculares In: LEONARDO, M.R.; LEAL, J.M. Endodontia: tratamento de canais radiculares. 3 ed. São Paulo: Panamericana, 1998. Cap. 20, p. 335-342.

MAISTO,Oscar: Preparacion de los conductos radiculares. In: ENDODONCIA. 3. ed. Buenos Aires: Mundi, 1967. 154p.

PÉCORA,J.D; et.al. Estudo sobre o shelf life da solução de Dakin. Rev. Odontol. Univ. São Paulo, São Paulo, v.1, n.1, p.3-7, jan-mar, 1987.

PISKIN , B ; TURKÜN, M. Stability of various sodium hypochlorite solutions. J. Endod., Baltimore, v.21, no.5, p.253255,May, 1995.

SIQUEIRA Jr, J.F.; LOPES, H.P. Substâncias químicas empregadas no preparo dos canais radiculares. Rio de Janeiro: MEDSI, 1999. p.371-376.

SIQUEIRA, E. L.; NICOLETTE, M.A.; SANTOS, M. dos. Estabilidade química da solução de hipoclorito de sódio a $0,5 \%$ em função do PH. Pesq. Odontol. Brasil., São Paulo, v. 14, supl. 14, p. 153 , 2000.

SÓ, M.V.R. et al.Tissue dissolution ability of sodium hypoclorite from different manufactures. Braz .End.J, Goiânia, v.2 no.2, p.33- 34, 1997.

SÓ, M.V.R.; OSDEBERG, A.; KLYMUS, M. Verificação do teor de cloro disponí- vel em diferentes soluções de hipoclorito de sódio de diferentes marcas comerciais. JBC, Curitiba, v.4, n.24,p.32-4, Nov-Dez, 2000.

Endereço para correspondência: Prof. José Antonio Poli de Figueiredo Faculdade de Odontologia - UFRGS Rua Ramiro Barcelos, 2492 e-mail: endofig@terra.com.br 